\title{
Special issue "Solar-terrestrial environment prediction: toward the synergy of science and forecasting operation of space weather and space climate"
}

\author{
Kanya Kusano ${ }^{1 *}$, Mamoru Ishii ${ }^{2}$, Tomas Berger ${ }^{3}$, Yoshizumi Miyoshi ${ }^{1}$, Shigeo Yoden ${ }^{4}$, Huixin Liu ${ }^{5}$, \\ Terry Onsager ${ }^{6}$ and Kiyoshi Ichimoto ${ }^{7}$
}

\begin{abstract}
The space environmental variability (widely called "space weather") can influence the electromagnetic environment around the earth and human life. In particular, a severe space weather event caused by a large solar eruption is a potential risk to social infrastructures such as artificial satellites, aviation, electric power, communications, and positioning systems. Furthermore, it has been pointed out that long-term variation in the solar cycle may affect the global environment. Therefore, predicting the solarterrestrial environment is important not only as scientific research, but also for sustaining a safe and secure modern society. However, the mechanism of solar-terrestrial environmental dynamics and its influence on the socioeconomic system is not yet fully understood.

The special issue "Solar-Terrestrial Environment Prediction: Toward the Synergy of Science and Forecasting Operation of Space Weather and Space Climate" is a comprehensive summary of the current status of research on this issue. In Japan, a nation-wide joint project "the Project for Solar-Terrestrial Environment Prediction (PSTEP)" was conducted from 2015 to 2019 in order to improve this situation through synergy between the basic science research and the forecast operation. In this special issue, the various research papers of this project and the related studies are compiled as follows.
\end{abstract}

\footnotetext{
*Correspondence: kusano@nagoya-u.jp

${ }^{1}$ Institute for Space-Earth Environmental Research (ISEE), Nagoya

University, Nagoya 464-8601, Japan

Full list of author information is available at the end of the article
}

Kusano et al. (2021) summarized the major research achievements of PSTEP about the space weather forecasting system, the prediction of solar storm and geospace dynamics, solar cycle activity and its climate impact. The scale of space weather events and their occurrence rate in Japan was surveyed by Ishii et al. (2021), in which the information for the space weather disaster defense was assembled.

One of the major space weather impacts on the society is caused by geomagnetic induced current (GIC). Watari et al. (2021) overviewed GIC measurement systems and reported several examples of the measurements in substations around Tokyo, Japan. Yagova et al. (2021) analyzed GIC in a transformer at the terminal station at Vykhodnoy, Russia, during the entire year of 2015 and found that large-scale pulsations are more effective in GIC generation than small-scale pulsations. Kikuchi et al. (2021) observed the electromagnetic disturbance caused by the geomagnetic sudden commencement (SC) using the high-frequency (HF) Doppler sounders at middle and low latitudes and confirmed that the electric field signal propagates near-instantaneously (within $10 \mathrm{~s}$ ) over the globe.

The evaluation of the influence of energetic particles on satellites and aircraft is an important task for the space weather forecast. Nagatsuma et al. (2021) developed the Space Environment Customized Risk Estimation for Satellites (SECURES) system by combining models of the space environment and those of spacecraft charging. 
Saito et al. (2021) estimated the economic impact of atmospheric radiation storm associated with solar energetic particle (SEP) events on aircraft operations by using the Warning System for AVIation Exposure to Solar energetic particle (WASAVIES). Oka et al. (2021) analyzed an unusual short-duration SEP event and found that the higher-energy $(>30 \mathrm{MeV})$ protons were detected about four hours after the shock arrival of ICME. The impact of energetic particle precipitation on atmospheric chemistry was investigated by Tsuda et al. (2021) and they found that the Na loss around the topside of $\mathrm{Na}$ layer would be induced by the energetic particle precipitation.

Many papers on the ionospheric dynamics and its prediction are published by this special issue. Nishioka et al. (2021) statistically analyzed the extreme states of ionospheric total electron content (TEC) in Japan. Tao et al. (2020b) also analyzed the statistics of short-wave fadeout for extreme space weather event estimation. Otsuka et al. (2021) studied the solar activity dependence of mediumscale traveling ionospheric disturbances (MSTID) using GPS receivers in Japan. Hosokawa et al. (2020) monitored the anomalous propagation of aeronautical VHF radio waves due to sporadic $E$ layer in Japan.

The Ground-to-topside model of Atmosphere and Ionosphere for Aeronomy (GAIA) is a powerful tool to simulate and predict the dynamics of ionosphere and atmosphere. Shinagawa et al. (2021) developed the numerical prediction of sporadic $\mathrm{E}$ layer occurrence using the GAIA. Ghosh et al. (2020) investigated the day-to-day variation of pre-reversal enhancement in the equatorial ionosphere based on GAIA model simulations. Sivakandan et al. (2021) compared the seasonal and longitudinal variation of daytime MSTID activity using GPS observation and GAIA simulations. Tao et al. (2020a) reported the numerical forecast of the upper atmosphere and ionosphere using GAIA, in particular for ionospheric storms and sudden stratospheric warming.

The solar cycle dynamics and solar eruptions are the major cause of space weather variation in the long term and short term, respectively, and their prediction is one of the most important subjects in this special issue. The variability of solar differential rotation and meridional flow were analyzed by Imada et al. (2020) using the magnetic element feature tracking technique. Seki et al. (2021) studied the relationship between three-dimensional velocity of filament eruptions and CME based on the Doppler observations. A new infrared observation for solar polarimetry was developed by Hanaoka et al. (2020).

Nishizuka et al. (2021) reported the operational solar flare prediction model using Deep Flare Net. Watanabe et al. (2021) reported the model-based reproduction and validation of the total spectra of a solar flare and their impact on the global environment. Nishimoto et al. (2021) examined the computed extreme ultraviolet emission spectra during solar flares. The advanced method for the CME arrival-time forecasts was developed based on the assimilation of magnetohydrodynamic simulations and the interplanetary scintillation observations by Iwai et al. (2021).

It is also crucial to investigate the details of the severe space weather phenomena that occurred in the past from the literature and records for considering countermeasures against future space weather disasters. Hayakawa et al. (2020) reported the record of south American aurora during the Carrington storm. Oliveira et al. (2020) investigated a possible case of sporadic aurora observed at Rio de Janeiro. Kataoka (2020) statistically analyzed extreme geomagnetic activities.

As mentioned already, solar-terrestrial environment prediction is necessary to protect the future society. However, for its development, the cooperation between various related research fields and their applications is essential. This special issue summarizes the latest efforts for it. We hope that further study will progress through the synergy between scientific research and the operational forecast of space weather.

Acknowledgements
This work was supported by JSPS KAKENHI Grant 20H05604.

Authors' contributions

$\mathrm{KK}, \mathrm{MI}, \mathrm{TB}, \mathrm{YM}, \mathrm{SY}, \mathrm{HL}, \mathrm{TO}$, and $\mathrm{KI}$ served as guest editors for this special issue. All authors read and approved the final manuscript.

\section{Competing interests}

The authors declare that they have no competing interests.

\section{Author details}

${ }^{1}$ Institute for Space-Earth Environmental Research (ISEE), Nagoya University, Nagoya 464-8601, Japan. ${ }^{2}$ National Institute of Information and Communications Technology (NICT), Koganei, Tokyo 184-8795, Japan. ${ }^{3}$ Space Weather Technology Research and Education Center, University of Colorado at Boulder, Boulder, CO 80309, USA. ${ }^{4}$ Institute for Liberal Arts and Sciences, Kyoto University, Kyoto 606-8501, Japan. ${ }^{5}$ Earth and Planetary Science Division, Kyushu University, Fukuoka 819-0395, Japan. ${ }^{6}$ Space Weather Prediction Center, NOAA, Boulder, CO 80305, USA. ${ }^{7}$ Astronomical Observatory, Kyoto University, Kyoto 606-8502, Japan.

Received: 5 October 2021 Accepted: 5 October 2021

Published online: 25 October 2021

\footnotetext{
References

Ghosh P, Otsuka Y, Mani S, Shinagawa H (2020) Day-to-day variation of pre-reversal enhancement in the equatorial ionosphere based on GAIA model simulations. Earth Planets Space 72:93. https://doi.org/10.1186/ s40623-020-01228-9

Hanaoka Y, Katsukawa Y, Morita S, Kamata Y, Ishizuka N (2020) A HAWAll-2RG infrared camera operated under fast readout mode for solar polarimetry. Earth Planets Space 72:181. https://doi.org/10.1186/s40623-020-01318-8 Hayakawa H, Ribeiro JR, Ebihara Y, Correia AP, Sôma M (2020) South American auroral reports during the Carrington storm. Earth Planets Space 72:122. https://doi.org/10.1186/s40623-020-01249-4
} 
Hosokawa K, Sakai J, Tomizawa I, Saito S, Tsugawa T, Nishioka M et al (2020) A monitoring network for anomalous propagation of aeronautical VHF radio waves due to sporadic E in Japan. Earth Planets Space 72:88. https://doi.org/10.1186/s40623-020-01216-z

Imada S, Matoba K, Fujiyama M, lijima H (2020) Solar cycle-related variation in solar differential rotation and meridional flow in solar cycle 24. Earth Planets Space 72:182. https://doi.org/10.1186/s40623-020-01314-y

Ishii M, Shiota D, Tao C, Ebihara Y, Fujiwara H, Ishii T et al (2021) Space weather benchmarks on Japanese society. Earth Planets Space 73:108. https://doi. org/10.1186/s40623-021-01420-5

Iwai K, Shiota D, Tokumaru M, Fujiki K, Den M, Kubo Y (2021) Validation of coronal mass ejection arrival-time forecasts by magnetohydrodynamic simulations based on interplanetary scintillation observations. Earth Planets Space 73:9. https://doi.org/10.1186/s40623-020-01345-5

Kataoka R (2020) Extreme geomagnetic activities: a statistical study. Earth Planets Space 72:124. https://doi.org/10.1186/s40623-020-01261-8

Kikuchi T, Chum J, Tomizawa I, Hashimoto KK, Hosokawa K, Ebihara Y et al (2021) Penetration of the electric fields of the geomagnetic sudden commencement over the globe as observed with the HF Doppler sounders and magnetometers. Earth Planets Space 73:10. https://doi.org/10.1186/ s40623-020-01350-8

Kusano K, Ichimoto K, Ishii M, Miyoshi Y, Yoden S, Akiyoshi H et al (2021) PSTEP. project for solar-terrestrial environment prediction. Earth Planets Space 73:159. https://doi.org/10.1186/s40623-021-01486-1

Nagatsuma T, Nakamizo A, Kubota Y, Nakamura M, Koga K, Miyoshi Y et al (2021) Development of space environment customized risk estimation for satellites (SECURES). Earth Planets Space 73:26. https://doi.org/10. 1186/s40623-021-01355-x

Nishimoto S, Watanabe K, Kawai T, Imada S, Kawate T (2021) Validation of computed extreme ultraviolet emission spectra during solar flares. Earth Planets Space 73:79. https://doi.org/10.1186/s40623-021-01402-7

Nishioka M, Saito S, Tao C, Shiota D, Tsugawa T, Ishii M (2021) Statistical analysis of ionospheric total electron content (TEC): long-term estimation of extreme TEC in Japan. Earth Planets Space 73:52. https://doi.org/10.1186/ s40623-021-01374-8

Nishizuka N, Kubo Y, Sugiura K, Den M, Ishii M (2021) Operational solar flare prediction model using Deep Flare Net. Earth Planets Space 73:64. https://doi.org/10.1186/s40623-021-01381-9

Oka M, Obara T, Nitta NV, Yashiro S, Shiota D, Ichimoto K (2021) Unusual enhancement of $\sim 30 \mathrm{MeV}$ proton flux in an ICME sheath region. Earth Planets Space 73:31. https://doi.org/10.1186/s40623-021-01362-y

Oliveira DM, Hayakawa H, Bhaskar A, Zesta E, Vichare G (2020) A possible case of sporadic aurora observed at Rio de Janeiro. Earth Planets Space 72:82. https://doi.org/10.1186/s40623-020-01208-z

Otsuka Y, Shinbori A, Tsugawa T, Nishioka M (2021) Solar activity dependence of medium-scale traveling ionospheric disturbances using GPS receivers in Japan. Earth Planets Space 73:22. https://doi.org/10.1186/ s40623-020-01353-5

Saito S, Wickramasinghe NK, Sato T, Shiota D (2021) Estimate of economic impact of atmospheric radiation storm associated with solar energetic particle events on aircraft operations. Earth Planets Space 73:57. https:// doi.org/10.1186/s40623-021-01377-5

Seki D, Otsuji K, Ishii TT, Asai A, Ichimoto K (2021) Relationship between threedimensional velocity of filament eruptions and CME association. Earth Planets Space 73:58. https://doi.org/10.1186/s40623-021-01378-4

Shinagawa H, Tao C, Jin H, Miyoshi Y, Fujiwara H (2021) Numerical prediction of sporadic E layer occurrence using GAIA. Earth Planets Space 73:28. https://doi.org/10.1186/s40623-020-01330-y

Sivakandan M, Otsuka Y, Ghosh P, Shinagawa H, Shinbori A, Miyoshi Y (2021) Comparison of seasonal and longitudinal variation of daytime MSTID activity using GPS observation and GAIA simulations. Earth Planets Space 73:35. https://doi.org/10.1186/s40623-021-01369-5

Tao C, Jin H, Miyoshi Y, Shinagawa H, Fujiwara H, Nishioka M et al (2020a) Numerical forecast of the upper atmosphere and ionosphere using GAIA. Earth Planets Space 72:178. https://doi.org/10.1186/s40623-020-01307-x

Tao C, Nishioka M, Saito S, Shiota D, Watanabe K, Nishizuka N et al (2020b) Statistical analysis of short-wave fadeout for extreme space weather event estimation. Earth Planets Space 72:173. https://doi.org/10.1186/ s40623-020-01278-z

Tsuda TT, Tanaka Y-M, Tozu R, Takizawa K, Ejiri MK, Nishiyama T et al (2021) Relationship between Na layer and CNA variations observed at Syowa. Antarctic Earth Planets Space 73:7. https://doi.org/10.1186/ s40623-020-01335-7

Watanabe K, Jin H, Nishimoto S, Imada S, Kawai T, Kawate T et al (2021) Modelbased reproduction and validation of the total spectra of a solar flare and their impact on the global environment at the X93 event of September 6 . Earth Planets Space 73:96. https://doi.org/10.1186/s40623-021-01376-6

Watari S, Nakamura S, Ebihara Y (2021) Measurement of geomagnetically induced current $(\mathrm{GIC})$ around Tokyo, Japan. Earth Planets Space 73:102. https://doi.org/10.1186/s40623-021-01422-3

Yagova NV, Pilipenko VA, Sakharov YA, Selivanov VN (2021) Spatial scale of geomagnetic Pc5/Pi3 pulsations as a factor of their efficiency in generation of geomagnetically induced currents. Earth Planets Space 73:88. https://doi. org/10.1186/s40623-021-01407-2

\section{Publisher's Note}

Springer Nature remains neutral with regard to jurisdictional claims in published maps and institutional affiliations.

\section{Submit your manuscript to a SpringerOpen ${ }^{\circ}$ journal and benefit from:}

- Convenient online submission

- Rigorous peer review

- Open access: articles freely available online

- High visibility within the field

Retaining the copyright to your article

Submit your next manuscript at springeropen.com 